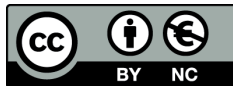

\title{
Evaluating Student Mentoring as an Intervention to Support Modern Foreign Language Learning in Secondary Schools in Wales
}

\author{
SALLY BLAKE and CLAIRE GORRARA \\ Cardiff University
}

\begin{abstract}
Commissioned annually by the British Council, the third Language Trends Wales report (2017) paints a worrying picture for non-indigenous languages in schools in Wales. Between 2002 and 2016, entries for modern foreign language qualifications at age sixteen (GCSE) dropped by $48 \%$. Entries for advanced qualifications (A Level) at age eighteen have seen a similar drop, with the number today now half that of 2005. Funded by the Welsh Government, a student mentoring project is working in Wales to improve the uptake of modern foreign languages at GCSE in schools where uptake is low or in decline. This article evaluates the outcomes of this mentoring project over its first two phases (2015-16 and 2016-17). It analyses this mentoring initiative from two perspectives. Firstly, it examines the project as a strategic policy intervention, targeted at increasing uptake of modern foreign languages at GCSE and supporting curriculum reform in Wales. Secondly, the article assesses mentoring as a personal and professional intervention, supporting the lifelong learning of university students who were trained as mentors to work in secondary schools. By reviewing the impact of the project on both mentees and mentors, the article makes a case for mentoring as an intervention with capacity to build partnerships, broaden horizons and improve attitudes to language learning at a time of uncertainty about the UK's and Wales's place in the world.
\end{abstract}


Keywords: mentoring, modern foreign languages, secondary schools, Higher Education, Wales

\section{Introduction}

Commissioned annually by the British Council, the third Language Trends Wales report paints a worrying picture for non-indigenous languages in schools in Wales (Board and Tinsley, 2017). Between 2002 and 2016, entries for modern foreign language qualifications at age sixteen (GCSE) have dropped by $48 \%$. Entries for advanced qualifications (A Level) at age eighteen have seen a similar drop, with the number today now half that of 2005. The biggest declines have been in French and German, the staple modern foreign languages of Welsh secondary education. These statistics mask significant regional and demographic variations. Schools in areas of higher socio-economic deprivation face the greatest challenges in terms of modern foreign languages take up and attainment (Miller, 2013). Funded by the Welsh Government, a student mentoring project has been working across Wales to improve the uptake of modern foreign languages at GCSE in schools where uptake is low or in decline.

This article evaluates the outcomes of the mentoring project over its first two phases (2015-16 and 2016-17). It analyses this initiative from two perspectives: firstly, as a strategic policy intervention to increase uptake of modern foreign languages at GCSE. How successful has the project been in raising uptake in the partner schools? To what extent has it helped build partnership across the education sector in support of modern foreign languages and curriculum reform? How far has it broadened pupils' horizons, particularly at a time when the national context and debates around Brexit have the potential to narrow them? Secondly, the article analyses mentoring as a personal and professional intervention, supporting the lifelong learning of mentors. What has mentoring achieved specifically for the university student mentors? How might it affect future careers and personal development journeys? The article, therefore, looks at the impact of the project on both mentors and mentees. 
The modern foreign languages mentoring project in Wales: project parameters and aims

The modern foreign languages student mentoring project has run over two school cycles thus far, with a third cycle being undertaken in 2017-18 at the time of writing of this article. It has an academic lead at Cardiff University who provides strategic oversight and is delivered on the ground by a National Coordinator, in collaboration with partners in the participating universities, educational consortia and secondary schools. In its first phase (January 2016 to March 2016), the project placed 32 undergraduate modern foreign linguists from Aberystwyth, Bangor, Cardiff, and Swansea universities in 28 schools across Wales to deliver a six-week programme of mentoring to pupils aged thirteen and fourteen (Years 8 and 9). Mentoring was timed to take place prior to decisions over GCSE subject choices when pupils could opt to stop learning modern foreign languages. In this first phase, 136 pupils were mentored. In its second phase, with two waves of mentoring (November to December 2016 and January 2017 to March 2017), the project placed 52 university mentors in 54 schools. This equated to an undergraduate student mentor active in a quarter of all secondary schools in Wales. In this phase, 868 pupils were mentored. Schools were nominated for the programme by strategic leads for modern foreign languages in Wales's four regional education consortia: CSC (South West Wales), EAS (South East Wales), ERW (Mid and West Wales) and GWE (North Wales). The National Coordinator then worked with modern foreign language teachers in the nominated schools to select pupils from groups who are traditionally under-represented in GCSE modern foreign languages classrooms, such as boys, those eligible for free school meals or able and talented pupils doubtful about the benefits of language learning (Board and Tinsley 2015: 11).

University mentors were recruited from the four participating university Schools of Modern Foreign Languages. The project targeted final-year students who had had the experience of living, working and studying abroad. Each mentor was awarded a small bursary from the Welsh Government project fund to take part in the programme. A robust training and support system for the mentors was put in place. It is known that mentor training is key to programme success and needs to encompass 'personal learning, personal skill development, personal identity growth' (Haggard et al., 2011, 300). An initial intensive weekend of training was followed by top-up training days at the participating universities, giving 
mentors the opportunity to share experiences on the ground. Following training, each mentor was paired by the National Coordinator with a school within the radius of their home university, ideally with a match between the languages they were studying at university and the languages studied in school.

A group mentoring mode was adopted for the project (Dubois et al., 2002). Such a model minimised concerns around safeguarding and child safety, whilst fostering the development of a supportive relationship between mentors and mentees who were closer in age than in a typical pupil-teacher mode. This model has been found to suit adolescent learners (Houlston, Smith and Jessel, 2009). In addition, it was hoped that mentee groups would encourage enthusiasm and enjoyment for language learning in the wider school community. Working predominantly with small groups of three to six mentees, the mentors highlighted the value of modern foreign languages for personal and professional development. This included discussions about their language journey, career opportunities and the value of intercultural citizenship for pupils who are increasingly being positioned as global citizens within the school curriculum. The sessions lasted between 30 minutes and one hour depending on pupil availability and timetabling in school and were explicitly not teaching sessions, as the aim was to build rapport and understanding between mentor and mentees as fellow language learners. After each cycle of mentoring, mentees were invited to attend a Reward and Recognition ceremony at the home/hub university of their mentors, with certificates awarded, interactive language workshops and a tour of the university campus.

\section{Methodological considerations}

To evaluate the outcomes of the project, the research conducted to date has made use of qualitative and quantitative social science research methods. To gauge the outcomes of the project as a strategic policy intervention, external evaluation assessed whole pupil cohort attitudes towards modern foreign languages in pre-mentoring surveys in partner schools. This included collecting base-line data on potential GCSE option choices. The first phase of the mentoring project (2015-16) surveyed the mentee cohort in their first mentoring session and did not, therefore, provide a true baseline of attitudes to modern foreign languages as there would have been the aura effect of being selected for the intervention. In the second phase, 
whole year cohorts were surveyed, making the baseline data a more accurate reflection of responses before mentoring. This pre-mentoring survey was used to select mentees, primarily those who were unsure or inclined to drop modern foreign languages at age fourteen. In phase 1, 252 pupils responded to pre-mentoring surveys and in phase 2 , this number rose to 3,096. This cohort data enabled the outcomes for pupils mentored to be assessed alongside non-mentored pupils in the partner schools. At the end of each cycle of mentoring, external evaluation compared the percentage of mentees who elected to study a modern foreign language at GCSE against the whole cohort group so that the impact of mentoring could be assessed. In addition, in phase 1 , the external evaluator undertook a baseline survey with teachers in 29 schools on pupil attitudes and conducted semi-structured interviews with four mentors and two teachers. In phase 2, 16 schools new to the project completed a baseline survey and a further three mentors and four teachers were interviewed. Schools were required to provide regular updates on the numbers of pupils taking up (or not) modern foreign languages at GCSE, above all after options were known in the summer term. Such interviews and updates gave valuable further insight into the outcomes of mentoring and its impact on mentees in the classroom.

To complement the focus of the external evaluation on mentee attitudes and outcomes, further research was undertaken to capture the experience and reflections of mentors at four points in the second phase of mentoring (2016-17): at the start of the intensive weekend of training, after the weekend of training, between first and second mentoring phases and after the mentoring was completed. This gave a longitudinal perspective into the developmental journey of the mentors. From this, it was possible to assess how the undergraduate mentors created a mentoring classroom experience for pupils which was distinctive from teaching, whilst deriving sometimes unexpected personal learning from the process. Mentors were invited to reflect on their motivation to take part in the project, their perceptions of mentoring as a practice and their aspirations for themselves and their mentees. This research data also allowed for reported intentions to teach modern foreign languages before and after the mentoring experience. Mentor data was captured via paper-based questionnaires at the start of the training weekend, from discussion notes generated within small group mentor-led workshops in the weekend training and at top-up training days and via an on-line survey post-mentoring in the summer of 2017 to which 24 of 54 mentors responded. Questionnaires and surveys 
were designed with open questions to generate data on attitudes, values and experiences of modern foreign languages. Such data was analysed via a mixed mode of discourse analysis (current themes and preoccupations) and triangulation against the qualitative data coming from mentor interviews with the external evaluator.

\section{Modern foreign languages in Wales: a time of change}

The precarious situation for modern foreign languages in Wales today can be attributed largely to systemic factors that have eroded its status in the school curriculum (Gorrara, 2017). Welsh is compulsory from age three to sixteen in English medium schools; equally, English is compulsory from age seven to sixteen in Welsh medium schools. Yet the formal teaching of modern foreign languages only begins at age eleven on entry to both English and Welsh-medium secondary schools. ${ }^{1}$ To compound this, modern foreign languages are not compulsory beyond the age of fourteen. This compares less favourably with norms in other bilingual jurisdictions in Europe where learning a third language begins between the ages of seven and nine and lasts on average for ten to twelve years (Tomasi, 2017: 122-3). The time allocated to learning modern foreign languages in the school timetable is also under threat in Wales. 40\% of modern foreign languages teachers interviewed in 2015 reported that their school does not observe the two hours per week recommended by Estyn, HM Chief Inspector of Education and Training in Wales (Board and Tinsley, 2016: 10). The introduction of the Welsh Government's Literacy and Numeracy Framework in 2014 has also focused the minds of school senior leaders on so-called 'core subjects', English, Maths, Welsh and Science. This has diminished the standing of modern foreign languages. The further integration of the Welsh Baccalaureate in 2017 as a compulsory curriculum component in secondary schools has reduced option choices at age fourteen (from four to three) in many Welsh schools.

The fragile position of modern foreign language learning in the Welsh school curriculum has been recognised by Welsh policy makers. Since 2015, the Welsh Government has been delivering a five-year strategy for modern foreign languages. The Global Futures programme aims to raise the profile of modern foreign languages as an important subject from ages seven to sixteen and as a longer-term skill for career opportunities (Welsh Government, 2015). As a programme, it sits within a broader framework 
of curriculum reform being implemented in Wales following the Successful Futures curriculum review undertaken by Professor Graham Donaldson (Donaldson, 2015). Successful Futures proposes a radical overhaul of the current school curriculum, working towards an integrated model of delivery where previously discrete subjects are reorganised into six Areas of Learning and Experience (AoLE). Modern foreign languages will sit with English and Welsh as part of a Languages, Literacy and Communication area in the new curriculum to be implemented progressively from 2022 (Welsh Government, 2017). This systemic review offers the opportunity to rethink how language learning can be delivered across English, Welsh and modern foreign languages, with pupils making connections between languages rather than seeing them as unrelated subjects. With its aspiration for mentees to see themselves as global citizens, the mentoring project aligns with the educational ambitions of the developing new curriculum and its move away from an examinations-led syllabus towards a creative and holistic approach to learning.

\section{Models of mentoring: fitness for purpose for modern foreign language projects}

Mentoring has traditionally been regarded as an informal, one-to-one relationship between a more experienced, 'teacher, advisor, sponsor, exemplar' (Levinson, 1978: 97) and a mentee at an earlier life or career stage. In the early 1980s, Kram (1983) captured patterns, functions and experiences of informal workplace mentoring. Since then, mentoring has been examined in a variety of settings and professions (Ehrich, Handsford and Tennent, 2004). As formal schemes have grown, evidence from systematic evaluation has increased. Passey and Morris (2010) for example, reported on a similar model of university student and pupil group mentoring in the evaluation of the UK Aim Higher initiative, a non-subject specific project. Mentoring is now a term which defines a range of helping relationships, settings, client groups and modes of practice (Garvey, Stokes and Megginson, 2014). It was expected that this model of helping could be adapted to support the mentoring project objectives of broadening pupils' horizons through supporting modern foreign language learning. Moreover, mentoring offered the potential to equip the undergraduate mentors with transferable skills which they could revisit in future careers.

The modern foreign languages mentoring project draws on youth mentoring models to support young peoples' career aspirations and individual 
potential (Baker and Maguire, 2005) and their social-emotional, cognitive and identity development (Rhodes, 2002). Pupil peer mentoring in schools is commonplace and the project's focus on pupil engagement fits the use of undergraduate mentors. This allowed deployment of subject expertise by near-peer language learners who could also act as role models and ambassadors for modern foreign languages, Higher Education study and intercultural citizenship. The mentoring project also supported a project aspiration to bring higher and secondary education systems together, introducing a non-didactic learning intervention which was likely to be an unfamiliar experience for secondary school and undergraduate language learners alike. Adolescent mentoring in schools draws on the constructivist learning model of Vygotsky (1978), where the learning helper plays a guiding, non-directive role alongside the mentee. In doing so, they share a learning journey. To achieve this, mentors needed to distinguish their approach to learning support from their own experiences of receiving language teaching in both secondary and Higher Education. Studies looking at pupil expectation of mentors show that they anticipate an element of teaching as well as coaching (Wang and Millward, 2014) and that pupils are most comfortable with mentoring when the focus is on study rather than self (Fresko and Kowalsky, 1998). Rhodes et al. (2006) cite language learning as a specific context where mentoring has potential to succeed.

\section{The mentees' journey: raising uptake, building partnership and broadening horizons}

As Scanlon asserts about mentoring: 'all relationships are shaped by the environment in which they are set' (Scanlon, 2008: 58). This project was embedded in the strategic actions of the Global Futures programme and was designed to achieve two core objectives: to increase the number of pupils taking one or more modern foreign languages at GCSE and to broaden pupils' horizons by highlighting career and mobility opportunities available to those with modern foreign languages (Welsh Government, 2016: 5). Key to both objectives was strengthening the personal resilience of mentees as language learners. Added values or process objectives were identified as: creating sustainable links between Higher Education departments of Modern Languages and their partner secondary schools and offering employment experience to undergraduate modern linguists, above all for those considering teaching as a profession. Three areas stood 
out as evidence of support for the mentees' language journeys: increasing numbers taking modern foreign languages at GCSE, building partnership between schools and universities and broadening pupils' horizons at a time of national uncertainty and change about Wales's place in the world.

\section{Raising uptake}

With regards to the first core objective, to increase the numbers of pupils taking one or more modern foreign language at GCSE, results from the two phases of the project to date have demonstrated success. In the first year of the project, $57 \%$ of those pupils mentored elected to study a modern foreign language at GCSE. This was a significant increase on the national figure of $20 \%$ (see Table 1). This equated to 77 mentees of the 136 who were mentored, an increase of 21 pupils on the 56 mentees who had initially indicated that they would opt for modern foreign languages post-compulsory study in the pre-mentoring survey.

Table 1: modern foreign language mentoring project: option choices in phase 1, adapted from Tinsley, 2017a: 12

\begin{tabular}{lccccc}
\hline Consortium & $\begin{array}{c}\text { Pupils } \\
\text { mentored }\end{array}$ & $\begin{array}{c}\text { Initial data } \\
\text { available }\end{array}$ & $\begin{array}{c}\text { Originally } \\
\text { choosing } \\
\text { MFL }\end{array}$ & $\begin{array}{c}\text { Choosing } \\
\text { MFL post } \\
\text { intervention }\end{array}$ & $\begin{array}{c}\text { Proportion } \\
\text { opting/ } \\
\text { mentees }\end{array}$ \\
\hline CSC & 39 & 28 & 20 & 29 & $74 \%$ \\
EAS & 22 & 16 & 10 & 16 & $73 \%$ \\
ERW & 41 & 15 & 5 & 14 & $34 \%$ \\
GWE & 34 & 34 & 21 & 18 & $53 \%$ \\
TOTAL & 136 & 93 & 56 & 77 & $57 \%$ \\
\hline
\end{tabular}

In the second year of the project, 868 students were mentored. In the pre-mentoring survey, 158 pupils indicated that they would choose a modern foreign language at GCSE. Following mentoring, 437 pupils elected to choose a modern foreign language post-compulsory study, a rise of 187 pupils, taking the total cohort percentage electing a modern foreign language to $50 \%$ (see Table 2).

These results revealed that the project had significant impact across all regions of Wales. In phase 2, the number of pupils mentored choosing modern foreign languages at GCSE nearly doubled in two regional 


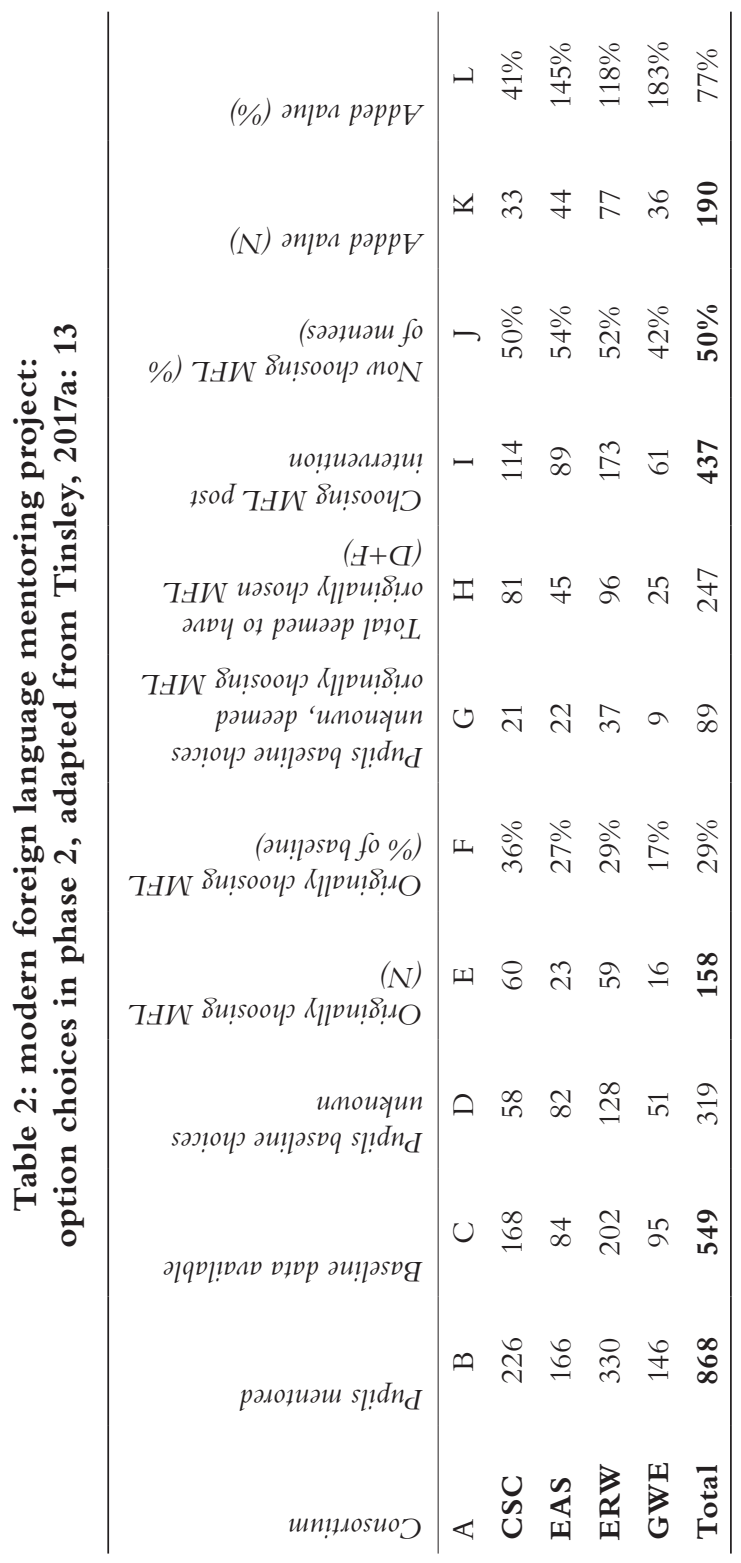


educational consortia (EAS and ERW) and in the case of GWE, in the North of Wales, numbers choosing a modern foreign language rose from $17 \%$ in pre-mentoring surveys to $42 \%$ in actual GCSE choices. In addition, the external evaluator calculated the number of additional pupils opting for modern foreign languages (column $\mathrm{K}$ ) as a proportion of the original number who said that they would choose a modern foreign language (column L). This represented an additional 187 pupils and an added value of $77 \%$ over the four regional education consortia.

The low take-up at GCSE in some schools prior to the mentoring intervention needs also to be factored in when looking at the success of the project. Over the two years of the project to date, four schools that had no GCSE modern foreign languages groups ran such a group after taking part in the project. In another school, although only four of 23 pupils mentored chose to take a modern foreign language at GCSE only six pupils in the whole year group choose to study a modern foreign language at GCSE (Tinsley, 2017a: 14).

Following the mentoring intervention, the number of pupils who continued to study a modern foreign language at GCSE could potentially have increased. Limiting factors external to the project had an impact (Tinsley, 2017a: 27-30). In some partner schools, senior leaders imposed minimal class sizes for optional subjects. This precluded smaller modern foreign language groups. In others, even when mentees had selected a modern foreign language at GCSE helping to generate a group, it was not permitted to run. This was due either to financial constraints and/or the organisation of option columns and school timetabling.

\section{Building partnership}

Beyond the quantitative data available on raising uptake, qualitative evidence points to the project's success in building partnership across the secondary school and university sectors to support younger learners of modern foreign languages. This moved beyond individual mentor and mentee partnership to impact on whole year cohorts in participating schools in a pyramid effect. Non-mentored pupils became interested by the world of the undergraduate students, as pupils who were being mentored spoke about their sessions and 'spread the word' about language learning with their peers. As reported in the external evaluator's report, teachers commented that mentoring had made modern foreign languages more visible within the school community, above all to senior leadership teams. 
One teacher is quoted as saying: 'the Head spoke about the Award Ceremony and the link between Science and Languages. Other pupils want to take part now' (Tinsley, 2017a: 24). Similarly, for academics in participating departments, mentoring energised them to propose further strategies to support modern foreign languages in Welsh schools. One such project was Cardiff University's turbo-tutoring project that supports attainment in modern foreign languages at AS level. ${ }^{2}$ Such cross-sectoral collaboration is known to encourage and support a multilingual approach to language learning (Kelly, 2015: 78). As research by Haggard et al. has demonstrated, one of the key attributes of mentoring is the development of 'mutuality of social exchange' (2011: 292) and the creation of a 'learning partnership' (2011: 293) which has benefited all participants.

\section{Broadening horizons}

Partnership between schools and universities has supported the second core objective of the mentoring project: to broaden the horizons of mentees by highlighting career and mobility opportunities for those with modern foreign languages. A mentoring ethos or mindset was integral to this objective as student mentors operated in a 'collaborative and collegial relationship' with their mentees, removed from the more formal hierarchical relationships of teaching (Scanlon, 2008: 57). 'Public knowledge' was not the goal of these interpersonal interactions but rather 'personal knowledge gained through experience' (Scanlon, 2008: 60). For the modern foreign languages project, this translated into mentors speaking honestly about their own language development and the transformative experience of living or working abroad. The impact of the mentor's life experiences on mentees' ambitions and life expectations was noted by teachers with one commenting: 'Our pupils are from the socially disadvantaged Valleys and, as such, a lot of them would be the first of their family to go to university. It was great for them to see that university is a real option for them and that travelling the world is open to all of them!' (Tinsley, 2017a: 23). In this context, the Reward and Recognition ceremonies at the hub universities played an important role in raising expectations. They highlighted the value of the mentor as a role model, able to embody life aspirations that extended beyond the local community of the mentees.

As the project has straddled the outcome of the Referendum on UK membership of the European Union, the national context was an 
additional factor to integrate into project development. Excepting Monmouthshire, Cardiff and the Vale of Glamorgan in the South, Ceredigion in mid-Wales and Gwynedd in the North, Wales voted to leave the European Union by $52.2 \%$ to $47.8 \%$. The liberal assumption that intercultural communication and language learning are innately positive was challenged by the outcome of the Referendum, where 'linguaphobia' was identified by some commentators as a contributory factor to the Leave vote (Forsdick 2017). Indeed, evidence from the project highlighted the limited understandings of language learning amongst some young people in Wales. In baseline school surveys, in phases 1 and 2, only a small percentage of teachers asserted that their pupils 'did not believe that languages would be useful to them in the future'. This was the case in three of 15 schools who responded in phase 1 and two of twenty-eight schools who responded in phase 2 (Tinsley, 2017a: 20-1). However, this translated largely into a perception of languages as a transactional commodity that would give pupils increased economic power - i.e. speaking a modern foreign language could increase their earning potential as young professionals. What was lacking in such responses was an understanding of languages as a door to other people's worlds and cultures. As one mentor reported to the external evaluator in an interview: '[Pupils] have never spoken French outside the classroom, have never seen films in French or listened to French music. They see language learning as academic, not alive' (Tinsley, 2017a: 22). This understanding of languages as 'alive', as personally and cognitively life-enhancing, was evident only in a minority of pupils. As research by Phipps and Fassetta has shown (2015: 15), seeing language learning via a 'discourse of skills' can lead to modern foreign languages being treated as tools rather than as central to intercultural understanding and personal development.

\section{The mentors' journey: learning and career benefits gained}

The mentoring project has needed to manage the desired strategic policy outcomes to improve modern foreign language take up at GCSE and broaden pupil horizons alongside support for the personal and professional development of mentors, some of whom could be future teachers. The data captured through the second phase illustrated how student mentors navigated the direct delivery of mentoring to younger language learners; how they adapted practice within the conventional modern foreign languages 
teaching environment in secondary schools and how they saw the benefit of involvement as role model modern linguists. Examples of the data from different survey points will be used here: respondent A data comes from questionnaires issued before the intensive weekend training, respondent $\mathrm{B}$ data from closing circles discussions at the end of the weekend training and respondent $\mathrm{C}$ data from an online survey after mentoring was completed.

\section{Mentor motivation: developing and reinforcing a language mission}

Effective mentors are known to be motivated by the desire to achieve something for themselves as well as others. Career and personal development are typical anticipated benefits (Eby and Lockwood, 2005; Scanlon, 2008). In the case of this project, career benefit was indeed a factor in attracting volunteers but a sense of mission also came from their identity as aspiring linguists. Data both pre- and post-mentoring was consistent in showing that the two most common reasons for volunteering were a desire to promote modern foreign languages and an interest in exploring or experiencing language teaching:

I was interested in being able to try teaching to get a better idea of what I could do with my degree. I hope to improve mentees' outlook on and proficiency of their language. (A5: pre-training questionnaire).

Their achievements in inspiring mentees through role modelling, promoting the importance of languages in broadening global and career horizons, was something mentors reported pride in:

I believe that the mentees have become more aware of the importance of languages and rather than see them as a chore or an inconvenience, I believe they will now use languages to benefit them in everyday life. (C18: post-practice).

It was clear that despite the project period falling under the shadow of the EU Referendum, passion for the subject remained a constant. In addition, mentors felt that, by using new learning resources, their own study skills had been strengthened, as well as their perception of the value of modern foreign languages.

I have realised how important and amazing learning languages are by reflecting. (C1: post-practice).

On both personal and mentorship levels, the mentors felt themselves to be 'bucking the trend'. The project provided an opportunity to reinforce their sense of identity as European linguists at a politically volatile time. 


\section{Mentoring and learning pedagogy}

For those who were exploring teaching, the exposure to secondary school learning and mentoring practices helped to foster a practical understanding of language pedagogy and application. Literature has suggested that, in a university context, mentoring is a term often used loosely and with little connection to career, professional identity development or learning theory (Trede et al., 2012; Johnson et al., 2007). In school, early modern foreign language learning requires skills development often supported by subject coaching and tutoring. However, these practices are not always clearly differentiated from mentoring. If, at the outset, the mentors could not readily separate directive teaching and 'hands-off' mentoring, after both their training and direct practice, they could articulate a clearer distinction between them. Some recognised mentoring as a valuable and potentially challenging practice:

Before this weekend I thought of a mentor as someone who simply instructed the mentee, rather than someone who pushed and challenged the mentee to think about their own skills (B6: training day, 'closing circles').

Before mentoring, I thought I may have to take on a teaching role ... however I understand that the mentor has a completely different but very significant responsibility ... working as a mentor means encouraging and inspiring the mentees. (C18: post-practice).

The mentors reported that, whilst they were equipped to meet pupils' expectation for a teaching focus when providing support with language skills, they could recognise how to step into a 'pure' mentoring mode to discuss global horizons and pupil aspirations (Wang and Millward, 2014). This proved crucial to pupil engagement. This ability to work with a blend of subject expertise and personal role modelling brought a learning experience to pupils which allowed them to see beyond skills, subject choices and exams into a future with potentially exciting life-enhancing experiences. As the external evaluator confirmed (Tinsley 2017a), it was this awareness-raising which was a key factor in shifting some pupils' mindsets away from a utilitarian view of learning a language. This was often the thinking of pupils who reported that they were inclined not to select a modern foreign language at GCSE.

For mentors who had sought classroom experience, the project also crystallised intentions to teach modern foreign languages. It gave them insight into the professional environment. Some mentors were inspired to consider teaching for the first time. However, some were deterred by the 
logistical challenges they experienced or by the realities of the professional environment:

It is always difficult to determine how long something will take - now I realise that you need a backup activity ... I heard about the pressures imposed on teachers by OFSTED. (C1: post-practice).

In Wales, mentorship of newly qualified teachers is supported by devolved educational policy. It is integral to new teacher induction (Welsh Government, 2012) and their postgraduate training (Cardiff University, 2014). The mentors could recognise the distinct advantage they would have because of their involvement in the project:

Such experience will enhance my employability in relation to teaching experience. (C19: post-practice).

The mentoring project acts as the initial point of my teaching journey that enables me to think and work as an academic. (C19: post-practice).

The project, therefore, gave some mentors the capacity to make more informed choices about teaching as a career choice. Importantly, the trend towards teaching was upwards in the surveys pre- and post-mentoring. This fulfilled one of the value-added project objectives: to engage with potential language teachers of the future.

\section{Wider career benefits for mentors}

The project also offered benefit to mentors in terms of generic employability skills, as anticipated in value-added project objectives. At the outset, mentors tended to express anticipated skills development in broad or functional terms such as:

improving my $\mathrm{CV}$, better understanding of teaching, improve my confidence and various skills. (A7: pre-mentoring).

The longitudinal data revealed a shift over time as mentors articulated a broader range of personal development outcomes. This draws on the principles of learning through reflective practice (Kolb, 1984; Schön, 1983). These principles were supported by the design of a mentor support programme, which allowed space for this deeper learning to happen.

By far the most consistent learning theme in the post-practice data was that of increased personal confidence:

I have gained so much more confidence and appreciated how difficult time-keeping is. (C1: post-practice). 
It's helped improve my self-confidence, as well as my organisation skills in planning for each session. (C4: post-practice).

My confidence has grown since becoming a mentor. I am more comfortable in public speaking and working with children. (C14: post-practice).

The more practical experience of managing practicalities on the ground provided an unplanned source of development (Blake, 2016). In top-up training, mentors reported issues such as an unexpected change in group size or time available, technology problems, 'crowd control' and poor organisation by the school. Mentors drew on personal resilience and resourcefulness to navigate their role in the face of these variables.

What might the future hold for the mentors? Current graduate career destination data (Prospects and AGCAS, 2016) suggests that modern foreign language students are amongst the most employable across sectors. They have a strong presence in marketing, business, sales and human resources. Student mentors were consistent in expressing an expectation that taking part in the project would provide them with enhanced CV evidence and transferable skills:

I envisage that it will provide me with more career options. (A12: pre-training).

It's very useful experience to have for future employers to see as it covers a wide range of skills. It's also given me a better appreciation of working with children. (C5: post-practice).

It has been extremely useful in job applications. (C7: post-practice).

Mentorship is a desired competence within professional standards and frameworks, including nursing, medicine and law. Experience and capability in mentoring was recognised by student mentors as a transferrable skill into professional life within or beyond teaching. They also saw mentoring as an enhancing personal development experience:

The mentoring project will be a highlight in my CV as it made me gain so many skills. I think these skills are useful in terms of both daily life and professional life. (C6: post-practice).

It is clear from the project findings that mentoring provided reciprocal benefits for mentors as well as their mentees. Moreover, it strengthened the mentors' sense of identity as linguists, teachers and aspiring professionals:

Mentoring is less similar to teaching than I thought but provides equally important knowledge and skills, just in a different way while being a role model (B5: post-training). 
The data also suggested that mentor learning from this process encompassed development of increased self-awareness and confidence which extended beyond linguistic and teaching competence. This is summed up by one student:

I have learned a lot about myself and my future career hopes. I have learned a lot about how much I know and how far I have come. I have learned my strengths and weaknesses as a linguist. (C8: post-practice).

\section{Conclusion}

This analysis of mentoring as an intervention to support modern foreign language learning in Wales has shown that the project has been successful as a strategic policy intervention in schools. Firstly, the project has highlighted the value of working across the educational sector to improve uptake and attitudes towards modern foreign languages for younger learners in Wales. Devolved government, universities, regional educational consortia and secondary schools working together have supported mentors and mentees to develop and mature as learners with benefits on both sides. Secondly, the project has helped improve not only subject awareness and uptake at GCSE but also has generated aspiration for further study amongst mentees. Interacting with universities through the mentor undergraduate demystified further study and gave a face and personality to the University sector which may have seemed unobtainable for some younger Welsh learners. Thirdly, the project has shown the reciprocal gains of mentoring for mentors. It has made a difference as a personal and professional intervention, supporting their life-long learning. They have derived personal satisfaction, increased commitment to learning languages and developed professional skills. These, one assumes, will all be of long-term benefit.

There are inevitably limiting factors for such a project as a sustained school intervention. These are bound up in systemic challenges, linked to the current configuration of the Welsh secondary school curriculum, such as option blocks and timetabling. These challenges will have constrained further uptake of modern foreign languages at GCSE. The project is also dependent on support and sponsorship from the Welsh Government-funded Global Futures programme which ends in 2020. But such considerations should not detract from where the mentoring project is having its greatest impact. By giving younger Welsh learners the opportunity to meet another European culture via a peer intermediary (the mentor), such pupils have 
been able to interrogate, appreciate and aspire to the mentor's passion for learning languages. Modern foreign language mentoring has opened a space for a shared excitement about language learning in the classroom and focused attention on the value of a 'locally situated multilingual perspective' (McLelland and Smith 2018: 3) on second language/foreign language learning. This perspective supports the Welsh Government's aspiration for a new Successful Futures curriculum driven by experiential learning and critical thinking. The project has also responded to the challenge of promoting intercultural understanding and citizenship in a time of uncertainty about the UK and Wales's place in the world. By demonstrating the life-enhancing opportunities of working, living and studying abroad, the university mentors have proven how language learning opens doors to other worlds. They have shown how such openness is attainable for all younger Welsh learners who aspire to be our informed global citizens of the future.

\section{References}

Baker, D.B. and Maguire, C.P. (2005). 'Mentoring in historical perspective', in D. DuBois and M. J Karcher, Handbook of Youth Mentoring, London, Sage, 14-29.

Blake, S. (2016). 'From expert to novice: supporting mentor development through professionalisation of practice in formal schemes', International Journal of Evidence Based Coaching and Mentoring (Special Issue 10), 1-15.

Board, K., Tinsley, T. (2017). Language Trends Wales 2016/17: The State of Language Learning in Secondary Schools in Wales, Cardiff, British Council Cymru/CfBT Education Trust.

Board, K., Tinsley, T. (2016). Language Trends Wales 2015/16: The State of Language Learning in Primary and Secondary Schools in Wales, Cardiff, British Council Cymru/CfBT Education Trust.

Board, K., Tinsley, T. (2015). Modern Foreign Languages in Secondary Schools in Wales. Findings from the Language Trends Survey 2014/15, Cardiff, British Council Cymru/CfBT Education Trust.

Cardiff University, Masters in Educational Practice http://walesmep.ac.uk/mentors/

Donaldson, G. (2015). Successful Futures. Independent Review of Curriculum and Assessment Arrangements in Wales. Cardiff, Welsh Government. http://gov.wales/ docs/dcells/publications/150225-successful-futures-en.pdf

DuBois, D. L., Holloway, B. E., Valentine, J. C. and Cooper, H., (2002). 'Effectiveness of mentoring programs for youth: a meta-analytic review', American Journal of Community Psychology, 30 (2), 157-97. 
Eby, L. T. and Lockwood, A. (2005). 'Protégés' and mentors' reactions to participating in formal mentoring programs: a qualitative investigation', Journal of Vocational Behavior, 67 (3), 441-58.

Ehrich, L. C., Hansford, B. and Tennent, L. (2004). 'Formal mentoring programs in education and other professions: a review of the Literature', Educational Administration Quarterly, 40 (4), 518-40.

Forsdick, C. (2017) 'Y Gymraeg a thwf "linguaphobia", http://www.bbc.co.uk/ cymrufyw/40801247.

Fresko, B. and Kowalsky, R. (1998). 'Helping high school pupils in the Perach Project: a comparison of mentoring and tutoring approaches', in Goodlad, S. (ed.), Mentoring and Tutoring by Students. London. Kogan Page, 33-48.

Garvey, B., Stokes, P. and Megginson, D. (2014). Coaching and Mentoring: Theory and Practice. London, Sage.

Gorrara, C. (2017). 'Speaking from Wales: building a modern languages community in an era of Brexit', in M. Kelly (ed.). Languages after Brexit. How the UK Speaks to the World. Basingstoke, Palgrave/Macmillan, 149-58.

Haggard, D. L., Dougherty, T. W., Turban, D. and Wilbanks, J. (2011). 'Who is a mentor? A review of evolving definitions and implications for research', Journal of Management, 37 (1), 280-304.

Houlston, C., Smith, P. K. and Jessel, J. (2009). 'Investigating the extent and use of peer support initiatives in English schools', Educational Psychology, 29 (3), $325-44$.

Johnson, W. B., Rose, G. and Schlosser, L. Z. (2007). 'Student-faculty mentoring: theoretical and methodological issues', in Allen, T. and Eby, L. (eds), The Blackwell Handbook of Mentoring: A Multiple Perspectives Approach. Chichester, Wiley Blackwell, 49-69.

Kelly M. (2015). 'Challenges to multilingual language teaching: towards a transnational approach', European Journal of Language Policy 7 (1), 65-83.

Kolb, D. A. (1984). Experiential Learning: Experience as the Source of Learning and Development. Upper Saddle River, NJ., Prentice-Hall.

Kram, K.E. (1983). 'Phases of the mentor relationship', Academy of Management Journal, 26 (4), 608-25.

Levinson, D. J. (1978). The Seasons of a Man's Life. New York, Knopf.

McLelland, N. and Smith R. (2018). 'Histories of language learning and teaching in Europe', The Language Learning Journal, 46 (1), 1-5.

Miller, C. (2013). 'Fall in foreign languages GCSE prompts fears for Wales's future prospects'. http://www.walesonline.co.uk/news/wales-news/fall-foreign-language-gcsesprompts- 2514337

Passey, R. and Morris, M. (2010). Evaluation of Aimhigher: Learner attainment and progression. National Foundation for Educational Research.

Phipps, A., Fasetta, G. (2015). 'A critical analysis of language policy in Scotland', European Journal of Language Policy, 7 (1), 5-27. 
Prospects and AGCAS (2016). What Do Graduates Do? Manchester.

Rhodes, J. E. (2002). Stand by Me: The Risks and Rewards of Mentoring Today's Youth. Cambridge, MA:, Harvard University Press.

Rhodes, J. E., Spencer, R., Keller, T. E., Liang, B. and Noam, G. (2006). 'A model for the influence of mentoring relationships on youth development', Journal of Community Psychology, 34 (6), 691-707.

Scanlon, L. (2008). 'The impact of experience on student mentors' conceptualistions of mentoring', International Journal of Evidence Based Coaching and Mentoring, $6(2), 57-66$.

Schön, D. A. (1983). The Reflective Practitioner: How Professionals Think in Action. New York, Basic Books.

Tinsley, T. (2017a). 'Raising the profile of modern languages, MFL mentoring initiative: evaluator's final report', July 2017, http://mflmentoring.co.uk/ research-publications.

Tinsley, T. (2017b). 'Turbo-tutoring: evaluation report', September 2017, unpublished.

Tomasi, L. (2017). 'The European Commission's language policy: challenges and priorities', European Journal of Language Policy, 9 (1), 121-31.

Trede, F., Macklin, R. and Bridges, D. (2012). 'Professional identity development: a review of the Higher Education literature', Studies in Higher Education, 37 (3), 365-84.

Vygotsky, L. S. and Cole, M. (1978). Mind in Society: The Development of Higher Psychological Processes. Cambridge, Mass.; London: Harvard University Press.

Wang, Q. and Millward, I. (2014). 'Developing a unified psychological model of coaching and mentoring in supporting the learning and development of adolescents,' International Journal of Evidence Based Coaching and Mentoring, 12 (2), 91-108.

Welsh Government (2012). Induction for Newly Qualified Teachers in Wales. Cardiff, Welsh Government.

Welsh Government (2015). Global Futures: A Plan to Improve and Promote Modern Foreign Languages in Wales 2015-2020. http://gov.wales/topics/educationandskills/ publications/guidance/global-futures-a-plan-to-improve-and-promote-modern-foreignlanguages-in-wales/?lang=en

Welsh Government (2016). Global Futures: A Year into our Plan - Annual Report. http://gov.wales/docs/dcells/publications/161213-global-futures-annual-report-en.pdf

Welsh Government (2017). A New Curriculum for Wales, The Story so Far ... http:// gov.wales/docs/dcells/publications/170707-new-curriculum-for-wales-story-so-faren-v2.pdf

Welsh Government (2017). Cymraeg 2050: A Million Welsh Speakers http://www. assembly.wales/Laid\%20Documents/GEN-LD11108/GEN-LD11108-e.pdf 


\section{Notes}

1 Welsh Government has recently announced investment in an ambitious programme for Welsh language learning. This has centred on increased funding for the Welsh-medium Coleg Cymraeg Cenedlaethol and an aspiration to produce one million Welsh speakers by 2050. For further information, see: http://www. assembly.wales/Laid\%20Documents/GEN-LD11108/GEN-LD11108-e.pdf

2 This project was designed to support pupils studying the new AS level modern language curriculum in Wales implemented in September 2016. Led by Cardiff University, the project provided an intensive tutoring programme for $8 \mathrm{sec}-$ ondary schools and 4 Further Education colleges to support the teaching of AS level French, from February to May 2017. The project was evaluated to have improved overall AS level grades of pupils by 0.33 of a grade and to have improved oral marks by 1 grade (Tinsley 2017b). The project was funded for a second year in 2018 by Welsh Government. 